\title{
The effects of preferential flow and soil texture on risk assessments of a NORM waste disposal site
}

\author{
E.M. Pontedeiro ${ }^{\mathrm{a}}$, M.Th. van Genuchten ${ }^{\mathrm{b}, *}$, R.M. Cotta $^{\mathrm{b}}$, J. Simunek $^{\mathrm{c}}$ \\ a Brazilian Nuclear Energy Commission, CNEN, Rua General Severiano 90, Rio de Janeiro, RJ 22290-901, Brazil \\ b Department of Mechanical Engineering, COPPE/LTTC, Federal University of Rio de Janeiro, UFRJ, Rio de Janeiro, RJ 21945-970, Brazil

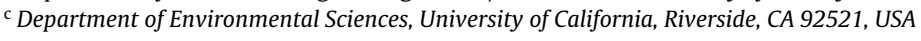

\section{A R T I C L E I N F O}

\section{Article history:}

Received 2 August 2009

Accepted 18 September 2009

Available online 9 October 2009

\section{Keywords:}

Radionuclide transport

NORM wastes

Preferential flow

Risk assessment

Solid waste disposal

\begin{abstract}
A B S T R A C T
This paper investigates the environmental fate of radionuclide decay chains (specially the ${ }^{238} \mathrm{U}$ and ${ }^{232} \mathrm{Th}$ series) being released from a conventional mining installation processing ore containing natural occurring radioactive materials (NORMs). Contaminated waste at the site is being disposed off in an industrial landfill on top of a base of earth material to ensure integrity of the deposit over relatively long geologic times (thousands of years). Brazilian regulations, like those of many other countries, require a performance assessment of the disposal facility using a leaching and off-site transport scenario. We used for this purpose the HYDRUS-1D software package to predict long-term radionuclide transport vertically through both the landfill and the underlying unsaturated zone, and then laterally in groundwater. We assumed that a downgradient well intercepting groundwater was the only source of water for a resident farmer, and that all contaminated water from the well was somehow used in the biosphere. The risk assessment was carried out for both a best-case scenario assuming equilibrium transport in a fine-textured (clay) subsurface, and a worst-case scenario involving preferential flow through a more coarse-textured subsurface. Results show that preferential flow and soil texture both can have a major effect on the results, depending upon the specific radionuclide involved.
\end{abstract}

(c) 2009 Published by Elsevier B.V.

\section{Introduction}

Much attention over the years has focused on the possible longterm effects of waste disposal on the environment and human health. Numerical models can be important tools for landfill designers and operators, as well as for environmental regulators, to predict the long-term subsurface transport of contaminants leached from solid waste disposal sites as a function of climatologic conditions and landfill design. Performance assessment is especially important for landfills containing radioactive mining wastes resulting from the processing of naturally occurring radioactive materials (NORM and TENORM wastes), often involving the $U$ and Th radionuclide decay series [1-3]. TENORM refers to technologically enhanced naturally occurring radioactive material in which human activities (e.g., mining of ores or drilling of oil and gas) have increased, in comparison to the altered state, the concentration of naturally occurring radionuclides, and/or enhanced the potential for radiation exposure to humans and biota [4].

A large number of models are now available to predict the transport of aqueous contaminants from solid waste landfills or similar

\footnotetext{
* Corresponding author.

E-mail address: rvangenuchten@yahoo.com (M.Th. van Genuchten).
}

facilities in soils and groundwater. They range from relatively simple mass balance models designed specifically for landfills, such as the HELP code [5], to more comprehensive multi-dimensional models for more general variably-saturated flow and contaminant transport problems, such as the TOUGH [6] and HYDRUS [7] families of codes. While these models have seen application to a wide range of problems, including for performance studies of waste disposal sites and capillary barriers, they have been used only sparingly in combination with detailed risk assessments of NORM waste sites $[1,8]$.

Safety or dose assessments for long time periods are essential for the management of long-lived NORM and TENORM contaminants. Since institutional controls may not last much longer than a few decades after site closure, the wastes are unlikely to remain safe. Natural leaching of radionuclides into the adjacent biosphere is almost certainly to occur within a few centuries or even earlier. Since NORM wastes in Brazil are typically deposited in industrial landfills, regulations require a safety assessment of the disposal facility using a leaching and off-site transport scenario.

In this paper we evaluate radionuclide transport from a NORM disposal site in Amazonia using the HYDRUS-1D numerical software package [9]. A sensitivity analysis is carried out of various factors affecting radionuclide transport, and indirectly the risk assessment, including soil texture and especially preferential flow 
through the waste layer, the vadose zone and the granular aquifer below and downgradient from the site.

\section{Mining site and disposal facility}

The radionuclide transport and safety assessment is applied here to a still operating NORM waste site located in the north of Brazil close to the equator. The analysis permits an evaluation of the potential consequences of slag disposal in a tropical forest. The exact location of the site is not given here for reasons of confidentiality. Ore extracted from an open pit mine at the site contains natural radionuclide decay chains, with the daughter products mostly in secular equilibrium with the parent. Different physical and chemical procedures (crushing/grinding, separation, concentration) are employed at the site to produce a final concentrate for pyrometallurgical processing. Pyrometallurgy involves treatment in a furnace at high temperatures to separate metals from large amounts of waste rock still present in the concentrate. The waste is most often removed in the form of slags in which all radioactive species have become more concentrated as compared to the original ore, except for radioactive lead which, together with its stable isotope, may be volatilized during the production process.

The radioactive components of the slag have long decay chains (14 daughters for the ${ }^{238} \mathrm{U}$ series) that end in stable lead. Modeling the transport of these contaminants hence should involve not only the parent nuclide, but also all of its daughter products. The calculations with the decay chains are not trivial since the daughter radionuclides formed during the decay process all have different physical and chemical properties. The daughters hence may move faster or slower than the parent in different layers of the disposal system and groundwater, while also having radiological toxicities that differ from those of the parent.

The concentrations of short-lived daughters were calculated from the activity of the parent nuclides (directly measured) using the assumption of secular equilibrium and applied to elements with half-lives of not more than 1 year. The general parent/daughter decay chain is of the form:

$$
\begin{aligned}
{ }^{238} \mathrm{U} & \rightarrow{ }^{234} \mathrm{Th} \rightarrow{ }^{234} \mathrm{~Pa} \rightarrow{ }^{234} \mathrm{U} \rightarrow{ }^{230} \mathrm{Th} \rightarrow{ }^{226} \mathrm{Ra} \rightarrow{ }^{222} \mathrm{Rn} \\
& \rightarrow{ }^{218} \mathrm{Po} \rightarrow{ }^{214} \mathrm{~Pb} \rightarrow{ }^{214} \mathrm{Bi} \rightarrow{ }^{214} \mathrm{Po} \rightarrow{ }^{210} \mathrm{~Pb} \rightarrow{ }^{210} \mathrm{Bi} \\
& \rightarrow{ }^{210} \mathrm{Po} \rightarrow{ }^{206} \mathrm{~Pb} \text { (stableelement) }
\end{aligned}
$$

In our analysis we limited ourselves to the chain ${ }^{238} \mathrm{U} \rightarrow{ }^{234} \mathrm{U}$ $\rightarrow{ }^{230} \mathrm{Th} \rightarrow{ }^{226} \mathrm{Ra} \rightarrow{ }^{210} \mathrm{~Pb}$. Activities of the various isotopes are reported here in units of $\mathrm{Bq} / \mathrm{l}$ for liquid-phase concentrations and $\mathrm{Bq} / \mathrm{g}$ for solid-phase concentrations.

The facility containing the slags consisted of a modular disposal unit constructed of earth materials. An impermeable liner placed under the waste layer (a requirement of the regulatory agency) was not considered in our analysis. Average annual precipitation measured at a location close to site was $2430 \mathrm{~mm}$, and the average evapotranspiration rate (as calculated with the Penman-Monteith equation) was $1610 \mathrm{~mm}$. Adjusted for runoff, the long-term average recharge rate at the site was estimated to be $657 \mathrm{~mm} / \mathrm{y}$. This recharge rate was used as a surface flux boundary condition for the steady-state simulations of water flow through the site and into groundwater.

The dimensions of the disposal unit were $70 \mathrm{~m}$ wide by $100 \mathrm{~m}$ long and $6.0 \mathrm{~m}$ deep. Initial radionuclide concentrations were $71 \mathrm{~Bq} / \mathrm{g}$ for ${ }^{238} \mathrm{U}$ and ${ }^{234} \mathrm{U}, 67 \mathrm{~Bq} / \mathrm{g}$ for ${ }^{230} \mathrm{Th}, 63 \mathrm{~Bq} / \mathrm{g}$ for ${ }^{226} \mathrm{Ra}$ and $4.8 \mathrm{~Bq} / \mathrm{g}$ for ${ }^{210} \mathrm{~Pb}$. These values suggest that $\mathrm{U}$ is likely in secular equilibrium with ${ }^{230} \mathrm{Th}$. Since ${ }^{226} \mathrm{Ra}$ is more mobile than the other radionuclides, there will be a loss of Ra by leaching. Because also some ${ }^{222} \mathrm{Rn}$ will escape through volatilization, both ${ }^{226} \mathrm{Ra}$ and ${ }^{222} \mathrm{Rn}$ will not be in equilibrium with ${ }^{210} \mathrm{~Pb}$ during the pyrometallurgi- cal process, and radioactive lead will volatize simultaneously with stable lead.

The slag waste layer had a measured bulk density of $1.89 \mathrm{~g} / \mathrm{cm}^{3}$. The unsaturated hydraulic properties of the waste layer and the underlying vadose zone were described using the constitutive equations [10]:

$$
\begin{aligned}
& S_{\mathrm{e}}(h)=\frac{\theta(h)-\theta_{\mathrm{r}}}{\theta_{\mathrm{s}}-\theta_{\mathrm{r}}}=\frac{1}{\left[1+(\alpha h)^{n}\right]^{m}} \quad\left(m=1-\frac{1}{n}\right) \\
& K(h)=K_{\mathrm{s}} S_{\mathrm{e}}^{0.5}\left[1-\left(1-S_{\mathrm{e}}^{1 / m}\right)^{m}\right]^{2}
\end{aligned}
$$

where $S_{\mathrm{e}}$ is effective saturation, $h$ is the pressure head, $\theta$ is the volumetric water content, $\theta_{\mathrm{r}}$ and $\theta_{\mathrm{s}}$ represent the residual and saturated water contents, respectively, $K_{\mathrm{s}}$ is the saturated hydraulic conductivity, and $\alpha$ and $n$ are empirical shape parameters [10]. Values of the hydraulic parameters of the waste layer were estimated from long-term drainage experiments on large lysimeters containing slags from the site, operated by the Poços de Caldas Laboratory of the Brazilian Nuclear Energy Commission (CNEN) in Minas Gerais, Brazil.

We also tried to estimate distribution coefficients ( $K_{\mathrm{d}}$ values) of the radionuclides from the lysimeter experiments with the slags, but the concentrations (except those of ${ }^{226} \mathrm{Ra}$ ) of the leachate were too low and too variable to obtain reliable estimates. Preliminary laboratory batch measurements at the Poços de Caldas Laboratory indicated radionuclide $K_{\mathrm{d}}$ values very close to those of a clay soil [11], except for Ra, which was closer to that of sand. For these reasons we used $K_{\mathrm{d}}$ values typical of clay for $\mathrm{U}$, Th, and $\mathrm{Pb}(1.6,5.8$, and $0.54 \mathrm{~m}^{3} / \mathrm{kg}$, respectively), and the measured value $\left(0.88 \mathrm{~m}^{3} / \mathrm{kg}\right)$ for $\mathrm{Ra}$. The same values were initially used for all layers (slag, vadose zone, aquifer). The assumed $K_{\mathrm{d}}$ values produced very high retardation factors $(R)$ factors for all of the radionuclides involved (up to about 40,000 for Th), and hence very low effective transport rates. In another analysis we also used the hydraulic parameters and $K_{\mathrm{d}}$ values of a typical coarse-textured (sandy) soil to show the very significant effects of soil texture on the simulations.

The unsaturated zone below the waste layer consisted of reddish Belterra clay as described by Dennen and Norton [12] and Truckenbrodt and Kotschoubey [13]. Although Oxisols such as those found at the site can have very high clay contents (up to 90\%), they often show relatively high infiltration rates more typical of coarse-textured soils, and considerable macroporosity. Soil texture (clay), bulk density $\left(1.3 \mathrm{~g} / \mathrm{cm}^{3}\right)$ and the saturated hydraulic conductivity $\left(K_{\mathrm{s}}=21 \mathrm{~m} / \mathrm{y}\right)$ of the vadose zone were locally measured. Other hydraulic parameters in Eq. (1) for Belterra clay were taken from Belk et al. [14], except for the value of $\alpha$ (we used $4.5 \mathrm{~m}^{-1}$ ), which was incorrectly printed in [14]. The hydraulic parameters in the Belk et al. paper were otherwise very much consistent with generic values suggested by Hodnett and Tomasella [15] and Tomasella et al. [16].

The saturated zone consisted of red saprolite resulting from in-situ alterations of acid volcanic rocks, interspersed with lightercolored (white, yellow) lenses derived from feldspars. The phreatic aquifer had an average thickness of $4.5 \mathrm{~m}$, with a natural hydraulic gradient of 0.05625 . Geotechnical essays of the aquifer produced values for the saturated hydraulic conductivity $\left(K_{\mathrm{S}}\right)$ between $4.22 \times 10^{-5}$ and $7.9 \times 10^{-4} \mathrm{~cm} / \mathrm{s}$. For our calculations we used a value of $1.7 \times 10^{-4} \mathrm{~cm} / \mathrm{s}$ for clay soil textural class as estimated with the pedotransfer function module of HYDRUS-1D, which is based on the hierarchical neural network (Rosetta) approach of Schaap et al. [17].

For the calculations we assumed a 6-m thick homogeneous waste layer (overlain by a negligibly thin layer of local soil), and a 5$\mathrm{m}$ thick unsaturated zone consisting of Belterra clay. Radionuclides leached vertically from the vadose zone were assumed to mix with 
laterally moving groundwater. The mixing process was described using the EPA mixing zone model [18]. Radiological doses and risks were calculated using a program for the biosphere based on recommendations by ISAM [11] and programmed [3] using the symbolic computational software Mathematica 5.2 [19]. We did not impose any time limits (e.g., 50,000 years) on our simulations; calculations for each scenario and radionuclide of interest in some cases continued until the peak value of the relevant safety indicator (dose) had been reached.

\section{Simulation methodology}

Water flow and radionuclide transport through the waste and vadose zone were simulated using the HYDRUS-1D software package [9]. Simulations assumed applicability of the Richards equation for flow in variably-saturated media as follows:

$$
\frac{\partial \theta(h)}{\partial t}=\frac{\partial}{\partial z}\left[K(h)\left(\frac{\partial h}{\partial z}-1\right)\right]
$$

where $z$ is the vertical coordinate positive downwards, $t$ is time, $h$ is the pressure head, $\theta$ is the volumetric water content, and $K(h)$ is the unsaturated hydraulic conductivity function given by Eq. (2). The transport of each radionuclide within the decay chain was initially modeled using the equilibrium advection-dispersion equation:

$\frac{\partial(\theta R C)}{\partial t}=\frac{\partial}{\partial z}\left(\theta D \frac{\partial C}{\partial z}\right)-\frac{\partial q C}{\partial z}+\phi$

where $C$ is the solution concentration, $R\left(=1+\rho K_{\mathrm{d}} / \theta\right)$ is the solute retardation factor, $\rho$ is the material bulk density, $K_{\mathrm{d}}$ is the distribution coefficient for linear equilibrium sorption, $D$ is the solute dispersion coefficient, and $q$ is the volumetric fluid flux density. The general reaction term $\phi$ represents first-order source-sink coupling of two consecutive radionuclides within the decay chain, with decay occurring in both the solution and adsorbed phases.

Eq. (4) assumes equilibrium transport. Unfortunately, much evidences exist that fluid flow and contaminant transport processes in the subsurface generally cannot be described using classical models that assume equilibrium or uniform flow conditions [20,21]. A large number of dual-porosity and dual-permeability models have been proposed to simulate preferential and/or non-equilibrium flow in soils and groundwater [21-23]. Here we limit our analysis to the concept of two-region (dual-porosity) transport involving physical non-equilibrium $[24,25]$. This approach assumes that the liquid-phase can be partitioned into mobile (macroporous, $\theta_{\mathrm{m}}$ ), and immobile (microporous or matrix, $\theta_{\mathrm{im}}$ ) regions, with $\theta=\theta_{\mathrm{m}}+\theta_{\mathrm{im}}$. Advective-dispersive transport is allowed only in the mobile phase, while the transfer of solute between the mobile and immobile region is controlled by diffusion. Assuming mobile/immobile type physical non-equilibrium, the governing transport equations for each radionuclide in the decay chain are now of the form [25]

$$
\frac{\partial\left(\theta_{\mathrm{m}}+f \rho K_{\mathrm{d}}\right) C_{\mathrm{m}}}{\partial t}=\frac{\partial}{\partial z}\left(\theta_{\mathrm{m}} D_{\mathrm{m}} \frac{\partial C_{\mathrm{m}}}{\partial z}-q C_{\mathrm{m}}\right)-\beta\left(C_{\mathrm{m}}-C_{\mathrm{im}}\right)+\phi_{\mathrm{m}}
$$

$\frac{\partial\left[\theta_{\mathrm{im}}+(1-f) \rho K_{\mathrm{d}}\right] C_{\mathrm{im}}}{\partial t}=\beta\left(C_{\mathrm{m}}-C_{\mathrm{im}}\right)+\phi_{\mathrm{im}}$

where the subscripts $\mathrm{m}$ and im refer to the mobile and immobile liquid phases, respectively, $f$ denotes the fraction of sorption sites in contact with mobile water, and $\beta$ is the average mass transfer coefficient for solute exchange between the mobile and immobile phases.

Eqs. (5) and (6) allow simulation of preferential or nonequilibrium transport in the subsurface with a minimum of
Table 1

Estimated values of the mass transfer coefficient, $\beta$, for radionuclide transport through the NORM waste and the Belterra clay subsurface.

\begin{tabular}{lllll}
\hline & ${ }^{238} \mathrm{U} /{ }^{234} \mathrm{U}$ & ${ }^{230} \mathrm{Th}$ & ${ }^{226} \mathrm{Ra}$ & ${ }^{210} \mathrm{~Pb}$ \\
\hline$\beta_{\text {waste }}\left(\mathrm{y}^{-1}\right)$ & 0.0016 & 0.0006 & 0.0026 & 0.0039 \\
$\beta_{\text {vadose }}\left(\mathrm{y}^{-1}\right)$ & 0.0025 & 0.0009 & 0.0041 & 0.0060 \\
$\beta_{\text {groundwater }}\left(\mathrm{y}^{-1}\right)$ & 0.0008 & 0.0003 & 0.0013 & 0.0019 \\
\hline
\end{tabular}

additional transport parameters. The model contains three additional parameters relative to the equilibrium model: $\theta_{\mathrm{m}}$ (or $\theta_{\mathrm{im}}$ ), $f$, and $\beta$. Following Nkedi-Kizza et al. [26], $f$ was set equal to the relative fraction of mobile water (i.e., $f=\theta_{\mathrm{m}} / \theta$ ), thus reducing the number of additional parameters to $2\left(\theta_{\mathrm{m}} / \theta\right.$ and $\left.\beta\right)$. In all of the calculations reported here we used a value of 0.5 for the fraction of mobile water, $\theta_{\mathrm{m}} / \theta$, which contrasts well with the equilibrium $\operatorname{approach}\left(\theta_{\mathrm{m}} / \theta=1\right)$. For $\beta$ we performed a sensitivity analyses using values from 0.001 (far from equilibrium) to 1 (close to equilibrium). In our final analysis we used values recommended by Maraqa [27] based on an analysis of previously published laboratory and fieldscale transport experiments. Maraqa found that the mass transfer coefficient $\beta$ is inversely related to the residence time of the contaminant in the system as follows:

$\beta=a t_{\mathrm{r}}^{-b}$

where $t_{\mathrm{r}}$ is the residence time in hours, and $b$ is in the range $0.73-0.88$ (we assumed a value of 0.8). Maraqa [27] estimated the value of $a$ to be 0.95 for fine non-aggregated media (assumed in our analysis), and 0.26 for aggregated media. Estimated values of $\beta$ for each radionuclide are listed in Table 1. Residence times in each of the three subsystems (waste layer, vadose zone, groundwater) were estimated using $t_{\mathrm{r}}=L R / v$, where $L$ is the length of the subsystem, $R$ is the retardation factor, and $v$ is the average pore water velocity $(v=q / \theta)$. Dispersivities were assumed to be one tenth of the length of each subdomain, while radionuclide half-life data were taken from ICRP [28].

\section{Transport simulation results}

The performance assessment of the disposal facility was carried out using a leaching and off-site small farm scenario. The system was modeled by assuming that rainfall percolated vertically downward through the disposal site and the unsaturated zone, and then mixed with and moved laterally in the aquifer. Radionuclides transported in groundwater were assumed to be intercepted by a well, located $100 \mathrm{~m}$ downgradient of the landfill. For the safety analysis we only used concentrations of the aquifer at the well point.

The first case considered equilibrium transport in each of the three media (the waste layer, the vadose zone, and groundwater). Calculated concentrations are shown in Fig. 1. Notice that ${ }^{238} \mathrm{U}$ and ${ }^{234} \mathrm{U}$ give by far the highest concentrations at both the bottom of the vadose zone and at the well. However, some contribution of ${ }^{230} \mathrm{Th}$ is also clearly present in the leachate from the vadose zone, but not at the well.

In order to analyze the impact of preferential flow on the final safety assessment, different cases were simulated using a mobile fraction of water (and an $f$ value) of 0.5 separately in each of the three layers. Figs. 2-4 show the effects of preferential flow in, respectively, the waste layer, the vadose zone only, and the aquifer only, assuming different values of the mass transfer coefficient $\beta$. The highest concentrations (especially for $U$ and $T h$ ) in the leachate leaving the waste layer were obtained when considering equilibrium (Fig. 2), or with relatively high values of the mass transfer coefficient $\beta$ (i.e., situations near equilibrium). This shows that preferential flow (small values of $\beta$ ) of rain water through the waste leads to less rapid pollution of the subsurface (i.e., rain water par- 

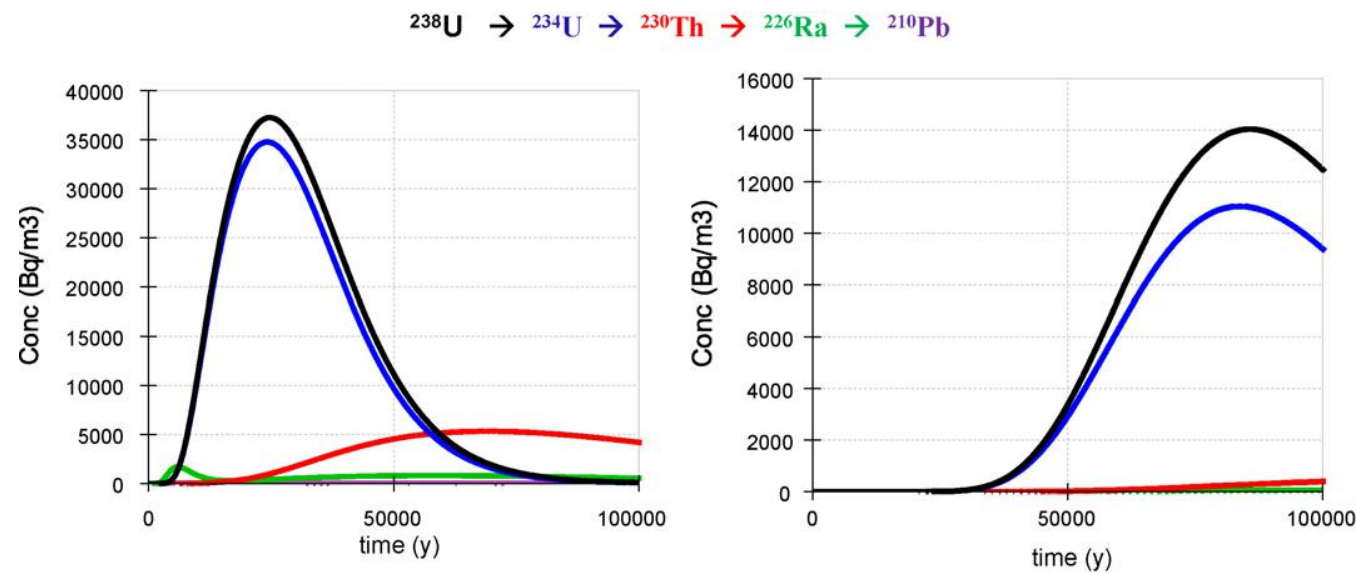

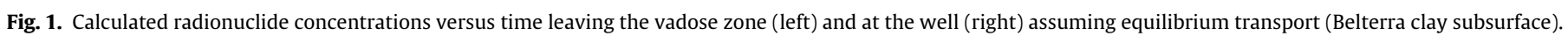

tially bypasses the waste). As compared to $\mathrm{U}$ and $\mathrm{Th}$, Ra and $\mathrm{Pb}$ were both found to decay very quickly.

Fig. 3 shows the effects of preferential flow through the unsaturated zone, while assuming equilibrium transport in the slags layer. Concentrations at the bottom of the vadose zone now progressively increase when $\beta$ decreases (more preferential flow). Notice that the front ends of the plumes arrive earlier for $U$ and $T h$, while for Ra and $\mathrm{Pb}$ the concentration peaks are higher because of shorter half-lives.

The effects of preferential flow in the aquifer (but with equilibrium transport in the slags and unsaturated zone) are shown in Fig. 4. Concentrations here pertain to a well $100 \mathrm{~m}$ downgradient from the waste site. The five radionuclides all behave very similarly, with the most rapid transport and highest concentrations occurring when $\beta=0.001 \mathrm{y}^{-1}$. The first peaks for ${ }^{226} \mathrm{Ra}$ and ${ }^{210} \mathrm{~Pb}$ at about 15,000 years were mostly due to advective-dispersive transport, while the increases after 30,000 years were a consequence of transport and decay of the predecessor radionuclides in the decay chain.

The sensitivity analysis for $\beta$ shows interesting results in that preferential flow of rain water through the waste layer leads to lower concentrations in the unsaturated zone below the waste layer, and in groundwater. On the other hand, preferential flow
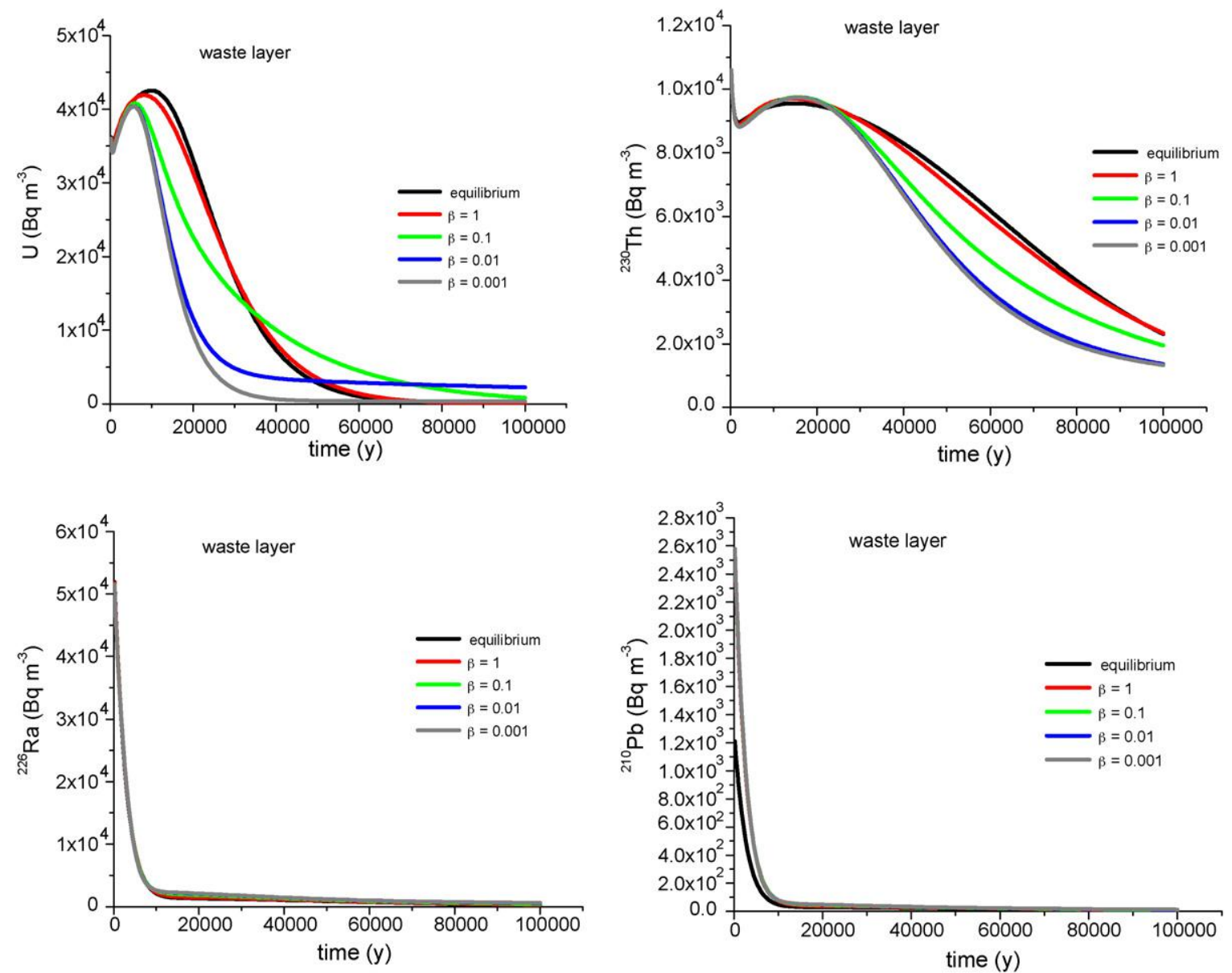

Fig. 2. Sensitivity analysis for preferential flow in the waste layer (Belterra clay). 

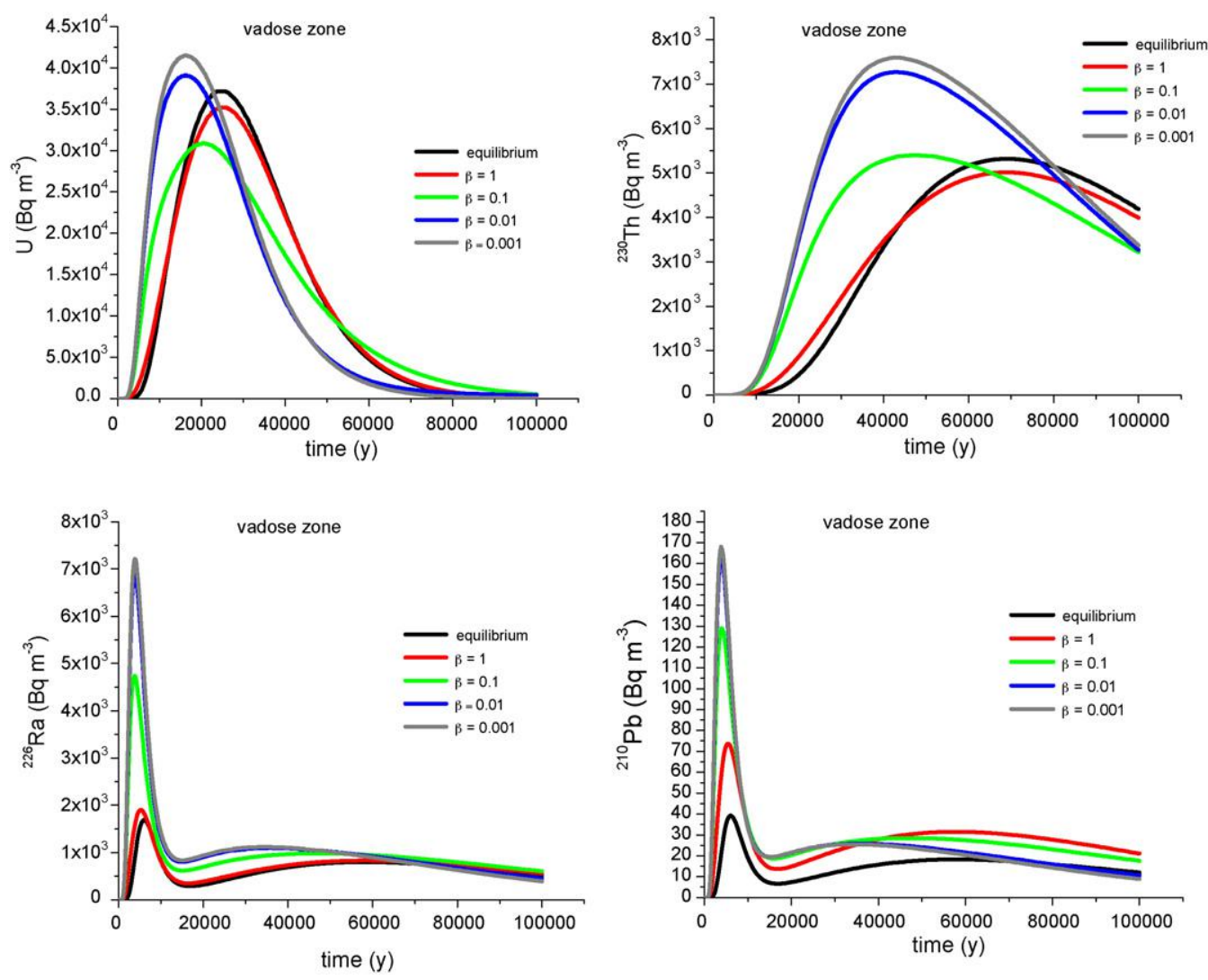

Fig. 3. Sensitivity analysis for preferential flow through the unsaturated zone below the waste layer (Belterra clay).

in the unsaturated and groundwater regions causes more rapid transport of the radionuclides, and higher peak concentrations. Fig. 5 shows the totality of the effects of preferential flow on the results using the values of $\beta$ as predicted with Eq. (7) and listed in Table 1. A comparison with the results for equilibrium transport (Fig. 1) shows that the peak concentrations for uranium (having the highest concentrations) are only marginally affected. However, the peak concentrations at the bottom of the vadose zone and espe-
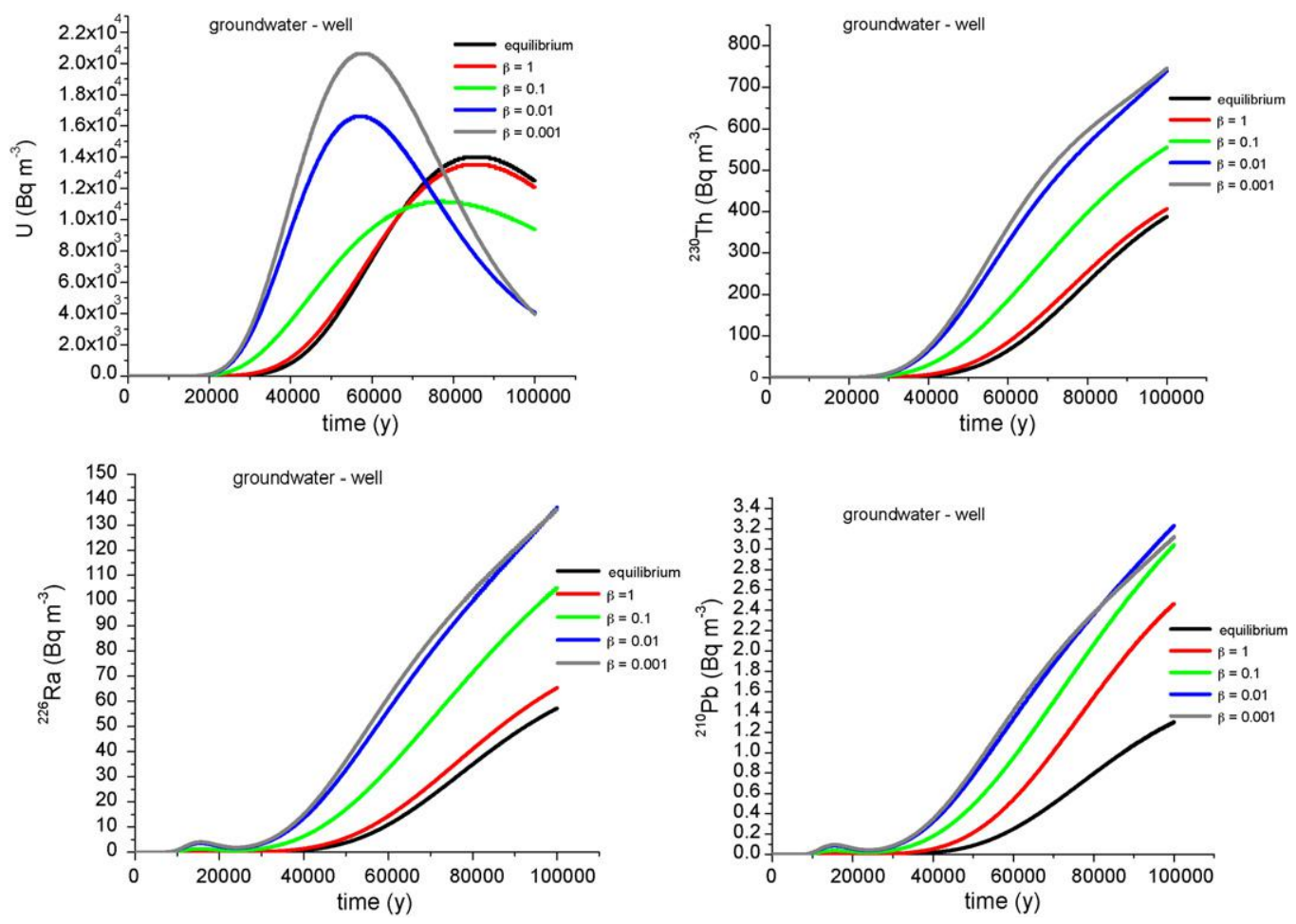

Fig. 4. Sensitivity analysis for preferential flow in the phreatic aquifer towards the well (Belterra clay). 

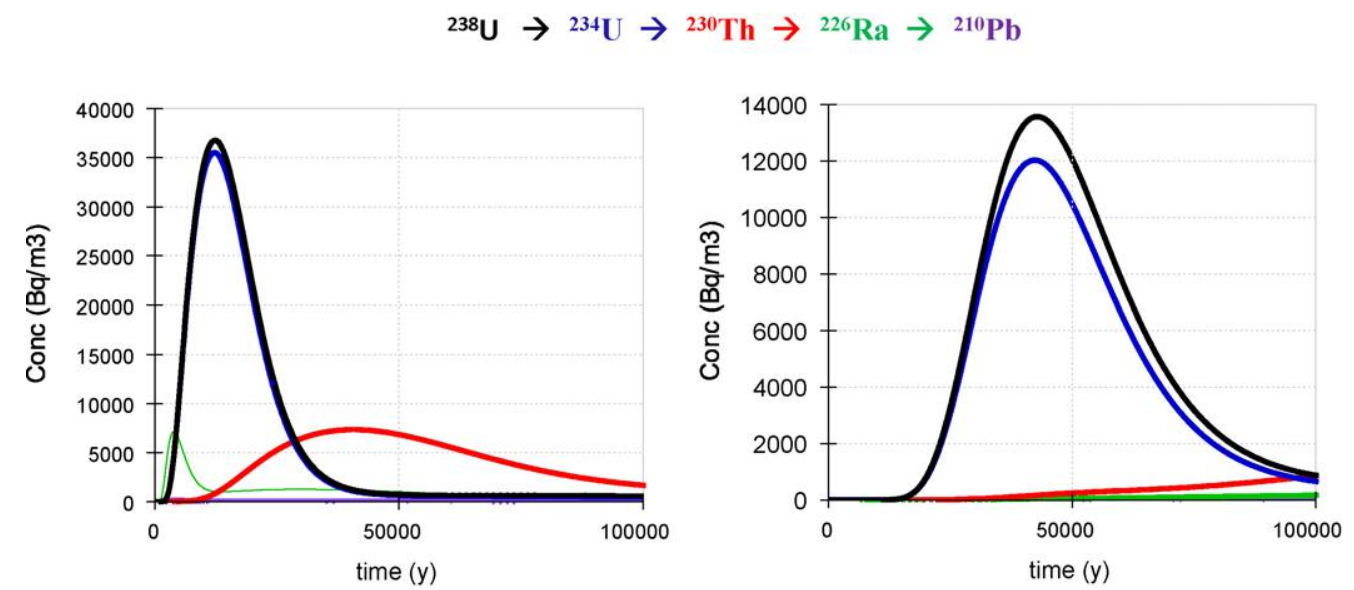

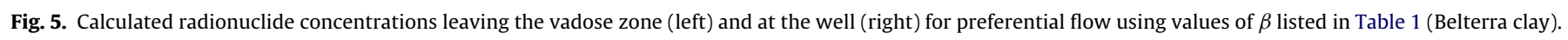
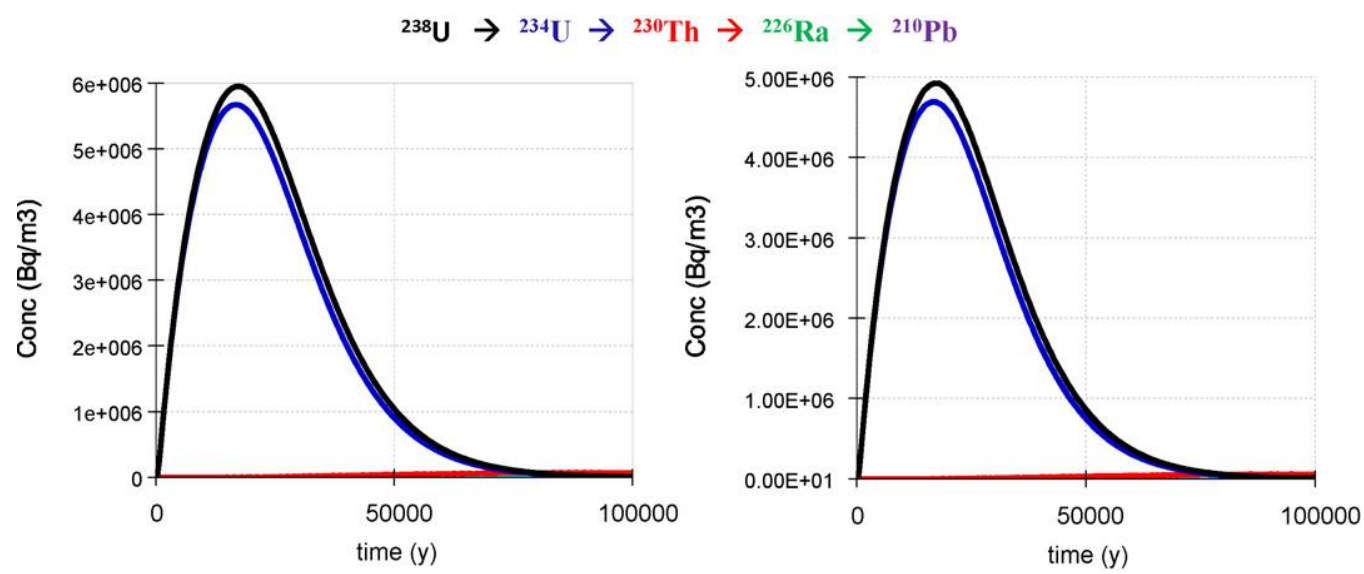

Fig. 6. Calculated radionuclide concentrations leaving the vadose zone (left) and at the well (right) assuming equilibrium transport (sand subsurface).

cially at the well (after 43,000 years for preferential flow versus 83,000 years for equilibrium transport) occur now much earlier. The radionuclides also arrived much earlier at the well $(12,500$ years for preferential flow versus 22,000 years for equilibrium transport).

All of the simulations so far were carried out for Belterra clay, leading to very conservative values for the hydraulic conductivity (permeability) and especially the estimated $K_{\mathrm{d}}$ values, and hence the contaminant transport rates. A complementary set of simulations was carried out to show the impact of soil texture on the long-term concentrations. For these simulations we assumed the presence of a very coarse-textured subsurface below the waste layer (i.e., for the vadose zone and groundwater), while leaving the physical and chemical properties of the waste layer itself unaltered. For $K_{\mathrm{d}}$ we selected typical literature values for sand: 0.035 , $3.2,0.5$ and $0.27 \mathrm{~m}^{3} / \mathrm{kg}$ for $\mathrm{U}, \mathrm{Th}, \mathrm{Ra}$ and $\mathrm{Pb}$, respectively, taken from ISAM [11]. For the unsaturated hydraulic properties in Eqs. (1) and (2) we used typical values for sand using the Rosetta module of HYDRUS-1D.

Results for equilibrium transport from the waste layer through the now sandy subsurface (vadose zone and aquifer) are shown in Fig. 6. As compared to the simulations for Belterra clay in Fig. 1, the ${ }^{238} \mathrm{U} /{ }^{234} \mathrm{U}$ peaks reach the bottom of the vadose zone much earlier (17,000 versus 24,000 years), while the peak concentration itself is $5.95 \times 10^{6} \mathrm{~Bq} / \mathrm{m}^{3}$, more than 100 times that for the clay soil $\left(3.72 \times 10^{4} \mathrm{~Bq} / \mathrm{m}^{3}\right)$. This reflects the much faster transport through the sandy vadose zone. Lateral transport rates through the aquifer are similarly much faster, with the ${ }^{238} \mathrm{U} /{ }^{234} \mathrm{U}$ peaks reaching the well $100 \mathrm{~m}$ downstream of the site now after only 18,000 years with a peak concentration of $4.92 \times 10^{6} \mathrm{~Bq} / \mathrm{m}^{3}$, compared to 85,000 years and a peak concentration of $1.4 \times 10^{4} \mathrm{~Bq} / \mathrm{m}^{3}$ for the Belterra clay subsurface.

We next superimposed the effects of preferential flow on the equilibrium results for the sandy subsurface shown in Fig. 6. As before, we estimated the values of the residence times in the vadose zone and the aquifer using Eq. (7), and then estimated the mass transfer coefficients using the correlations derived by Maraqa [8] for non-aggregated media (shown in Table 2). The value of $f$ was set at 0.5 , the same as for the clay soil. The results for preferential flow are shown in Fig. 7. Comparing these results with those in Fig. 6 for equilibrium transport shows that, similarly as for the Belterra clay subsurface, the peak concentrations are again only marginally higher for the preferential flow scenario (e.g., $4.6 \times 10^{6} \mathrm{~Bq} / \mathrm{m}^{3}$ for the sandy vadose zone compared to $3.7 \times 10^{4} \mathrm{~Bq} / \mathrm{m}^{3}$ for the clay). The peak concentrations however occur much earlier, especially at the well $(11,000$ years for the sandy subsurface versus 43,000 years for the clay). This shows that both soil texture and preferential flow can have major impacts on the radionuclide transport rates.

Table 2

Estimated values of the mass transfer coefficient, $\beta$, for radionuclide transport through the sandy subsurface of the waste disposal problem.

\begin{tabular}{lllll}
\hline & ${ }^{238} \mathrm{U} /{ }^{234} \mathrm{U}$ & ${ }^{230} \mathrm{Th}$ & ${ }^{226} \mathrm{Ra}$ & ${ }^{210} \mathrm{~Pb}$ \\
\hline$\beta_{\text {vadose }}\left(\mathrm{y}^{-1}\right)$ & 0.054 & 0.0015 & 0.0065 & 0.011 \\
$\beta_{\text {groundwater }}\left(\mathrm{y}^{-1}\right)$ & 0.34 & 0.0093 & 0.041 & 0.067 \\
\hline
\end{tabular}



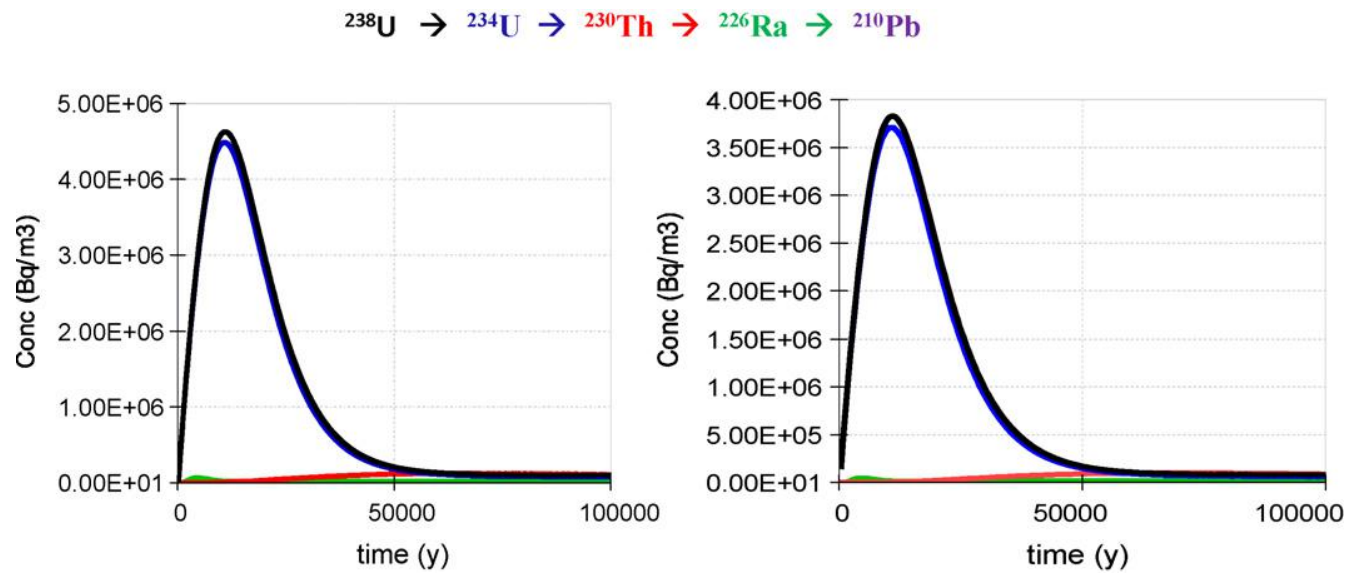

Fig. 7. Calculated radionuclide concentrations leaving the vadose zone (left) and at the well (right) for preferential flow (sand subsurface).

\section{Safety assessment}

The primary objective of a performance assessment is to provide evidence that human health and the environment are protected as much as possible in the future. This can be done only by carrying out simulations and using the results to judge if the adopted disposal concepts meet the radiological standards for long-term protection of the public and the environment, as established by regulatory bodies. A pathways analysis with different scenarios provides a systematic way of evaluating potential routes by which the human population could be exposed to radiation $[2,3,8]$. Because of the unpredictable nature of the long-term integrity of disposal systems, as well as of human behavior, the post-closure scenarios are inevitably hypothetical.

Our risk assessment of the NORM waste site assumes that the dose projection for members of the public cannot exceed $1 \mathrm{mSv} / \mathrm{y}$. Assuming a risk factor of $5 \%$ per Sievert (Sv) as recommended by the International Commission on Radiological Protection [28], this leads to an assessed radiological risk of fatality from the facility to a representative member of the potentially exposed group of $5 \times 10^{-5}$ (i.e., 5 in one hundred thousand per year). The acceptable fraction, termed the dose or risk constraint, shall be determined by the regulatory agency. The Brazilian regulatory body adopted a dose constraint of $0.3 \mathrm{mSv} / \mathrm{y}$ above natural background.

Our small farm scenario was modeled assuming that radionuclides migrated vertically through the disposal and vadose zones, and then laterally through the aquifer until intercepted by a well or discharged into a stream. We assumed that the well or stream provided the only available source of water for residents for direct consumption, irrigation or for use by cattle. The radiological dose was assessed for an exposed critical group of individuals in the population receiving the highest dose or risk. Data regarding human behaviour were based on the dietary habits of adults from that group (e.g., water and food consumption, breathing rate, and hours indoor or outdoor). Residents received doses from external radiation, ingestion of contaminated water and food, and inhalation
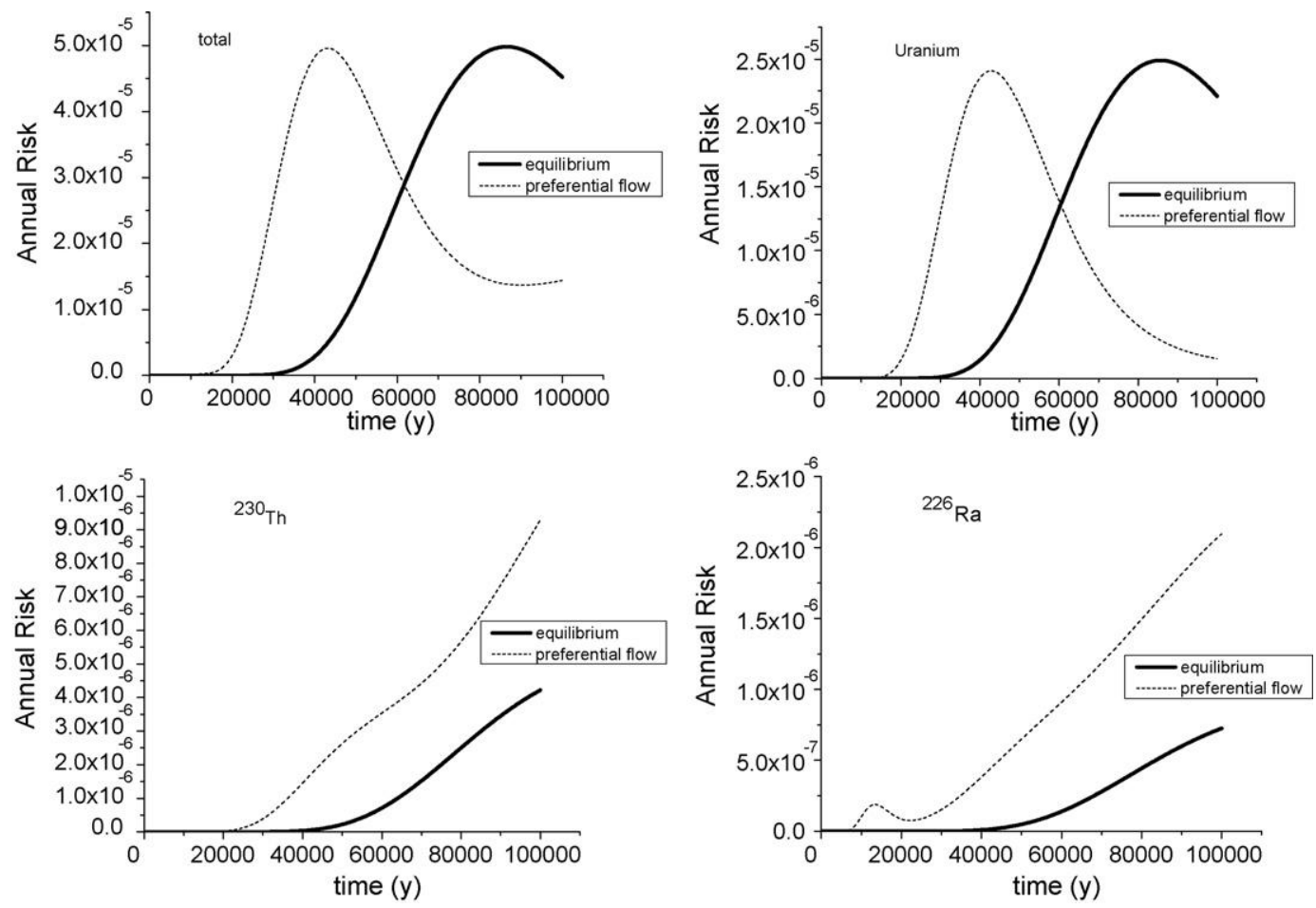

Fig. 8. Comparison of annual risk assuming either equilibrium transport or preferential flow (Belterra clay). 
of airborne radionuclides transported from the waste site or suspended in runoff water following irrigation. Following Pontedeiro et al. [3], the following specific processes in the biosphere were considered: (a) ingestion of water from the well, (b) irrigation, (c) re-suspension or particulates and inhalation, (d) external radiation exposure, (e) consumption of home-grown produce, (f) consumption of contaminated meat, $(\mathrm{g})$ ingestion of contaminated milk, (h) accidental ingestion of contaminated soil, (i) inhalation of radon and decay products from soil, and (j) contact with surface water, including transfer to fish and humans. Ingestion, inhalation and external dose conversion factors $\left(\mathrm{Sv} \mathrm{Bq}^{-1}\right)$, as well as transfer coefficients and concentration factors were taken from [11].

The risk assessment was performed for both equilibrium transport and the situation where preferential flow occurs simultaneously in all three subsurface systems (waste, vadose zone, groundwater). Results for the Belterra clay subsurface are presented in Fig. 8. The calculations show that Uranium is mostly responsible for the total dose up to 80,000 years. After that time the contribution of ${ }^{230} \mathrm{Th}$ becomes increasingly more significant, leading to approximately the same levels of total risk. The results in Fig. 8 further show that preferential flow causes the risks to shift to much earlier times, but that the maximum of the total annual risk is not substantially affected. This is also true for uranium but not for thorium and radium, which both show increasing annual risks over the considered time period of $100,000 \mathrm{y}$. Similar conclusions about the shifts to earlier times and the peak concentrations also hold if the subsurface was made up of more coarse-textured material, but such results are not shown here.

\section{Conclusions}

A major objective of this study was to illustrate the importance of having both a comprehensive process-based description of the fate and transport of NORM decay chains in the subsurface, and a detailed risk or dose analysis over relatively long periods of time (e.g., 50,000-100,000 years). The reliability of quantitative safety indicators such as those used here should of course decrease with time due to inherent uncertainties about future environmental conditions and human activities. The maximum annual risk over the 100,000 years period was approximately $5 \times 10^{-5}$ (a dose of $1 \mathrm{mSv} / \mathrm{y}$ ) for the Belterra clay subsurface at the Amazonian NORM waste site considered in this study. Since the dose constraint for NORM installations in Brazil is $0.3 \mathrm{mSv} / \mathrm{y}$ above natural background, the maximum calculated total doses and associated risks in our case study were always higher, irrespective of the assumption of having equilibrium or preferential flow in the subsurface, when a time frame of 100,000 years is considered. However, the maximum annual dose limit was not exceeded when restricting the calculations to only the first 50,000 years and assuming equilibrium transport.

Risk assessments are usually carried out assuming equilibrium transport in the subsurface. In this study we showed that preferential flow and soil texture can have a major effect by accelerating the transport of radionuclides in the unsaturated zone and the aquifer, thus affecting resultant concentrations and dose calculations. Similar major effects on transport and risk analyses are to be expected when other non-ideal transport processes are considered, such as chemical non-equilibrium and colloid-facilitated transport.

\section{References}

[1] C.J. Roberts, J.B. Quinby, W.P. Duggan, Y. Yuan, Disposal options and case-study pathway analyses, Appl. Radiat. Isotopes 49 (3) (1998) 241-258.
[2] Extent of environmental contamination by naturally occurring radioactive material (NORM) and technological options for mitigation, Technical Report Series No. 419, Int. Atomic Energy Agency, IAEA, Vienna, 2003 (available at http://www-pub.iaea.org/MTCD/publications/Pubdetails.asp?pubId=6789).

[3] E.M. Pontedeiro, P.F.L. Heilbron, R.M. Cotta, Assessment of mineral industry NORM/TENORM disposal in hazardous landfills, J. Hazard. Mater. B139 (2007) 563-568.

[4] E.R. Landa, Naturally occurring radionuclides from industrial sources: characteristics and fate in the environment, Radioactivity Environ. 10 (2007) 211-237 (Elsevier).

[5] P.R. Schroeder, T.S. Dozier, P.A. Zappi, B.M. McEnroe, S.J. Sjostrom, R.L. Peyton, Hydrologic Evaluation of Landfill Performance (HELP) Model, EPA/600/R-94/168, U.S. Environmental Protection Agency, Washington, DC, 1994.

[6] K. Pruess, The TOUGH codes; a family of simulation tools for multiphase flow and transport processes in permeable media, Vadose Zone J. 3 (2004) 738746.

[7] J. Simunek, M.Th. van Genuchten, M. Sejna, Development and applications of the HYDRUS and STANMOD software packages and related codes, Vadose Zone J. 7 (2008) 587-600.

[8] C. Yu, A.J. Zielen, J.-J. Cheng, Y.C. Yuan, L.G. Jones, DJ. LePoire, Y.Y. Wang, C.O. Loureiro, E. Gnanapragasam, E. Faillance, A. Wallo III, W.A. Williams, H. Peterson, Manual for implementing residual radioactive material guidelines using RESRAD, Version 5.0. ANL/EAD/LD-2, Argonne National Laboratory, Argonne, IL, 1993.

[9] J. Simunek, M.Th. van Genuchten, M. Sejna, The HYDRUS-1D Software Package for Simulating the One-Dimensional Movement of Water, Heat and Multiple Solutes in Variably-Saturated Media, Version 3.0. HYDRUS Software Series 1, Department of Environmental Sciences, University of California, Riverside, 2005, p. 240.

[10] M.Th. van Genuchten, A closed-form equation for predicting the hydraulic conductivity of unsaturated soils, Soil Sci. Soc. Am. J. 44 (1980) 892-898.

[11] Derivation of quantitative acceptance criteria for disposal of radioactive waste to near surface facilities: development and implementation of an approach, ISAM Safety Report, Version 3.0, IAEA, Vienna, Austria, March 1999.

[12] W.D. Dennen, H.A. Norton, Geology and geochemistry of bauxite deposits in the lower Amazon basin, Econ. Geol. 72 (1977) 82-89.

[13] W. Truckenbrodt, B. Kotschoubey, Cobertura terciária das bauxitas amazônicas, Revista Braileira Geociências 11 (1981) 203-208.

[14] E.L. Belk, D. Markewitz, T.C. Rasmussen, E.J.M. Carvalho, D.C. Nepstad, E.A. Davidson, Modeling the effects of throughfall reduction on soil water content in a Brazilian Oxisol under a moist tropical forest, Water Resour. Res. 43 (2007), doi:10.1029/2006WR005493 (W08432).

[15] M.G. Hodnett, J. Tomasella, Marked differences between van Genuchten soil water retention parameters for temperate and tropical soils: a new waterretention pedo-transfer function developed for tropical soils, Geoderma 108 (2002) 155-180.

[16] J. Tomasella, Ya. Pachepsky, S. Crestana, W.J. Rawls, Comparison of two techniques to develop pedotransfer functions for water retention, Soil Sci. Soc. Am. J. 67 (2003) 1085-1092.

[17] M.G. Schaap, F.J. Leij, M.Th. van Genuchten, Neural network analysis for hierarchical prediction of soil hydraulic properties, Soil Sci. Soc. Am. J. 62 (1998) 847-855.

[18] Soil Screening Guidance: Technical Background Document, EPA/540/R-95/128, PB96-963502, Office of Solid Waste and Emergency Response, U.S. Environmental Protection Agency, Washington, DC, 1996.

[19] S. Wolfram, Mathematica 5.2, Wolfram Media, Cambridge, UK, 2005.

[20] J.M.H. Hendrickx, M. Flury, Uniform and preferential flow mechanisms in the vadose zone, in: Conceptual Models of Flow and Transport in the Fractured Vadose Zone, National Academy Press, Washington, DC, 2001, pp. 149187.

[21] N.J. Jarvis, Review of non-equilibrium water flow and solute transport in soil macropores: principles, controlling factors and consequences for water quality, Eur. J. Soil Sci. 58 (2007) 523-546.

[22] J.Simunek, M.Th. van Genuchten, Modeling nonequilibrium flow and transport processes using HYDRUS, Vadose Zone J. 7 (2008) 782-797.

[23] J.M. Köhne, S. Köhne, J. Simunek, A review of model applications for structured soils: a) Water flow and tracer transport, J. Contam. Hydrol. 104 (2009) 435.

[24] M.Th. van Genuchten, P.J. Wierenga, Mass transfer studies in sorbing porous media. I. Analytical solutions, Soil Sci. Soc. Am. J. 40 (1976) 473-480.

[25] M.Th. van Genuchten, R.J. Wagenet, Two-site/two-region models for pesticide transport and degradation: Theoretical development and analytical solutions, Soil Sci. Soc. Am. J. 53 (1989) 1303-1310.

[26] P. Nkedi-Kizza, J.W. Biggar, M.Th. van Genuchten, P.J. Wierenga, H.M. Selim, J.M. Davidson, D.R. Nielsen, Modeling tritium and chloride 36 transport through an aggregated oxisol, Water Resour. Res. 19 (1983) 691-700.

[27] M.A. Maraqa, Prediction of mass-transfer coefficient for solute transport in porous media, J. Contam. Hydrol. 53 (2001) 153-171.

[28] Radionuclide Transformations Energy and Intensity of Emissions, Int. Commission on Radiological Protection ICRP Publication 38, Pergamon Press, Oxford, 1983. 